\title{
OPEN Author Correction: A Peptoid Delivers CoQ-derivative to Plant Mitochondria via Endocytosis
}

\section{Kinfemichael Geressu Asfaw, Qiong Liu, Jan Maisch, Stephan W. Münch, Ilona Wehl, Stefan Bräse, Ivan Bogeski, Ute Schepers \& Peter Nick}

Correction to: Scientific Reports https://doi.org/10.1038/s41598-019-46182-z, published online 08 July 2019

The original version of this Article omitted an affiliation for Ilona Wehl and Stefan Bräse. The correct affiliations for Ilona Wehl and Stefan Bräse are listed below:

Institute of Organic Chemistry, Karlsruhe Institute of Technology (KIT), Fritz-Haber-Weg 6, D-76131 Karlsruhe, Germany.

Institute of Toxicology and Genetics (ITG), Karlsruhe Institute of Technology (KIT), Hermann von Helmholtz Platz 1 D-76344 Eggenstein-Leopoldshafen, Germany.

Additionally, in the Supplementary Information file originally published with this Article the treatment in Supplementary Figure S1 was incorrectly listed as CoQ Peptoid.

These errors have now been corrected in the HTML and PDF versions of this Article, and in the accompanying Supplemental Material.

(i) Open Access This article is licensed under a Creative Commons Attribution 4.0 International License, which permits use, sharing, adaptation, distribution and reproduction in any medium or format, as long as you give appropriate credit to the original author(s) and the source, provide a link to the Creative Commons license, and indicate if changes were made. The images or other third party material in this article are included in the article's Creative Commons license, unless indicated otherwise in a credit line to the material. If material is not included in the article's Creative Commons license and your intended use is not permitted by statutory regulation or exceeds the permitted use, you will need to obtain permission directly from the copyright holder. To view a copy of this license, visit http://creativecommons.org/licenses/by/4.0/.

(c) The Author(s) 2019 